\title{
Nephrotic syndrome associated with Kimura's disease: a case report and literature review
}

\author{
Song Ren, Xin Yi Li, Fang Wang, Ping Zhang, Yuan Zhang, Gui Sen Li, Li Wang and Xiang Zhong*
}

\begin{abstract}
Background: Kimura's disease (KD) is a rare chronic inflammatory disorder with a high incidence of renal involvement. In this report, we present a case study of KD-associated nephrotic syndrome combined with minimal change disease (MCD) and acute renal tubular injury. Meanwhile, the clinical and histopathological characteristics of 26 patients with $\mathrm{KD}$ presenting with renal involvement were retrospectively evaluated.

Case presentation: Here, we report a case study of a 59-year-old male patient with KD confirmed by a lymph node biopsy. He developed widespread edema and decreased urine output. A palpable swollen mobile and non-tender lymph node behind the left ear was observed upon admission. A renal biopsy revealed minimal-change lesions and acute renal tubular injury. The patient received hemodialysis because of the oliguria and renal insufficiency, and an initial dose of $40 \mathrm{mg} / \mathrm{d}$ methylprednisolone and then continued treatment with $40 \mathrm{mg} / \mathrm{d}$ prednisolone. He exhibited a good clinical response to the steroid after 6 weeks of treatment. Of the other 26 patients included in the review, 13 patients presented with mesangial proliferative glomerulonephritis, 4 with membranous nephropathy, 3 with MCD, 3 with focal segmental glomerulosclerosis, 2 with IgA nephropathy and 1 with acute tubular injury. With the exception of 2 patients who progressed to end-stage renal disease and received hemodialysis, the majority of patients responded well to treatment with corticosteroids alone.
\end{abstract}

Conclusions: MCD combined with acute renal tubular injury is rare in patients with KD presenting with renal involvement. Corticosteroids may be a beneficial treatment for renal injury in patients with KD.

Keywords: Kimura's disease, Minimal change disease, Nephrotic syndrome, Prednisone

\section{Background}

Kimura's disease (KD), a rare chronic inflammatory disorder whose etiology is unknown, was first reported by Kim and Szeto in 1937. The disease has a higher prevalence in Asians [1]. KD typically presents as painless unilateral cervical lymphadenopathy or as subcutaneous masses in the head or neck region. The parotid glands and periauricular, axillary and inguinal lymph nodes are commonly affected $[2,3]$. KD is diagnosed based on the presence of a characteristic subcutaneous mass or palpable lymph node in conjunction with peripheral blood eosinophilia and elevated blood IgE concentrations [4].

\footnotetext{
* Correspondence: zxiang626@126.com

Department of Nephrology, Sichuan Academy of Medical Sciences \& Sichuan Provincial People's Hospital, School of Medicine, University of Electronic Science and Technology of China, No.32, West Section 2, Ring 1 Road, Chengdu 610072, Sichuan, China
}

Some patients may display renal involvement. The histological changes in the kidney associated with KD are heterogeneous and may be consistent with minimal change disease (MCD), membranous nephropathy, focal segmental glomerulosclerosis and IgA nephropathy [5-8].This paper presents a case of KD with MCD combined with acute renal tubular injury.

\section{Case report}

\section{Clinical features and laboratory findings}

A 59-year-old male patient presented with widespread edema and decreased urine output. The patient had no history of active arthritis, hemoptysis, bleeding, purpura, fever, chills, weight loss, streptococcal infection or known tropical disease and had not suffered from asthma or any other atopic diseases. At the time of his visit to our hospital, his blood pressure was 136/ 
$93 \mathrm{mmHg}$, and his temperature was $36.9^{\circ} \mathrm{C}$. The physical examination showed that the patient was suffering from left-sided hearing loss and revealed the presence of a palpable swollen mobile and non-tender lymph node with a size of approximately $1.5 * 1 \mathrm{~cm}$ located behind the left ear. No other superficial lymph nodes were palpable. A urinalysis showed $3+$ proteinuria and $3.68 \mathrm{~g}$ of proteinuria in $24 \mathrm{~h}$. The serum albumin (Alb) concentration was $11.3 \mathrm{~g} / \mathrm{L}$, the serum creatinine concentration was $218.7 \mu \mathrm{mol} / \mathrm{L}$, the BUN concentration was $25.33 \mathrm{mmol} / \mathrm{L}$, the eGFR was $27.4 \mathrm{~mL} / \mathrm{min} / \mathrm{m}^{2}$, and the ESR was $112 \mathrm{~mm} / \mathrm{h}$. The patient's serum complement (C3 and C4) levels, antinuclear antibody titers, antistreptolysin $\mathrm{O}$ titers, and hepatitis screening results were normal. Hematology revealed a normal hemoglobin concentration and platelet count, a total white blood cell count of $6.98^{*} 10 \mathrm{E} 9 / \mathrm{L}$, and a percentage of eosinophils of $6.6 \%$. The serum IgE concentration was elevated, as it was higher than $4000 \mathrm{IU} / \mathrm{mL}$. A Mycobacterium tuberculosis $\gamma$-interferon release test was negative, and a bone marrow biopsy did not display obvious abnormalities. A neck CT showed that the cervical vascular sheath was surrounded by several small lymph nodes, and an ultrasound demonstrated the presence of bilateral pleural effusions and ascites. Pleural effusion examination revealed a karyocyte count of $76 * 10 \mathrm{E} 6 / \mathrm{L}$, a neutrophil count of $12 \%$, a lymphocyte percentage of $85 \%$, an Alb concentration of $1.8 \mathrm{~g} / \mathrm{L}$, a lactate dehydrogenase (LDH) concentration of $44 \mathrm{U} / \mathrm{L}$, and an adenosine deaminase (ADA) concentration of $1.3 \mathrm{U} / \mathrm{L}$.

\section{Lymph node histological features}

Histological sections of lymph nodes were examined in the department of pathology. The examinations revealed the presence of follicular and interfollicular hyperplasia and the proliferation of venules surrounded by infiltrating eosinophils, lymphocytes, plasma cells, and mast cells. An eosinophilic microabscess was detected in the cortical area of the lymph nodes (Fig. 1). These findings confirmed the diagnosis of KD.

\section{Renal histology}

Renal biopsy showed that two glomeruli were sclerotic (13 glomeruli were assessed). The remaining glomerular mesangial cells and stromal cells showed signs of mild proliferation. No significant widening of the mesangial area was observed, and the basement membrane had no obvious lesions. The tubular epithelial cells displayed signs of vacuolization. Additionally, part of the renal tubular epithelium had flattened, and the bristles had fallen off. Small numbers of protein casts were present in the dilated tubules. No obvious interstitial inflammatory cell infiltration (including eosinophil infiltration) was present, and no IgG, IgA, IgM, C3, C1q, C4 or Fib deposition was noted in any of the glomeruli. Electron microscopy showed mild hyperplasia of mesangial cells and stromal cells, extensive fusing of the podocyte processes of the epithelial cells, and a lack of electron-dense deposits (Fig. 2).These findings confirmed the diagnosis of MCD combined with acute renal tubular injury.

\section{Treatment and follow-up}

The patient's volume load did not respond to diuretics, and his urine output decreased. Furthermore, increases in the patient's urea and creatinine levels were observed. Therefore, hemodialysis was initiated to improve the patient's edema and kidney function. The renal biopsy demonstrated the presence of MCD combined with acute renal tubular injury. The patient was ultimately diagnosed with KD associated with MCD and acute renal tubular injury. The patient subsequently received $40 \mathrm{mg} /$ day methylprednisolone for 3 weeks. Urinary protein and renal function were monitored during treatment, which decreased the patient's serum creatinine level to $62.3 \mu \mathrm{mol} / \mathrm{L}$, increased the eGFR to $103 \mathrm{~mL} / \mathrm{min} / \mathrm{m}^{2}$, increased the serum albumin concentration to $15.6 \mathrm{~g} / \mathrm{L}$
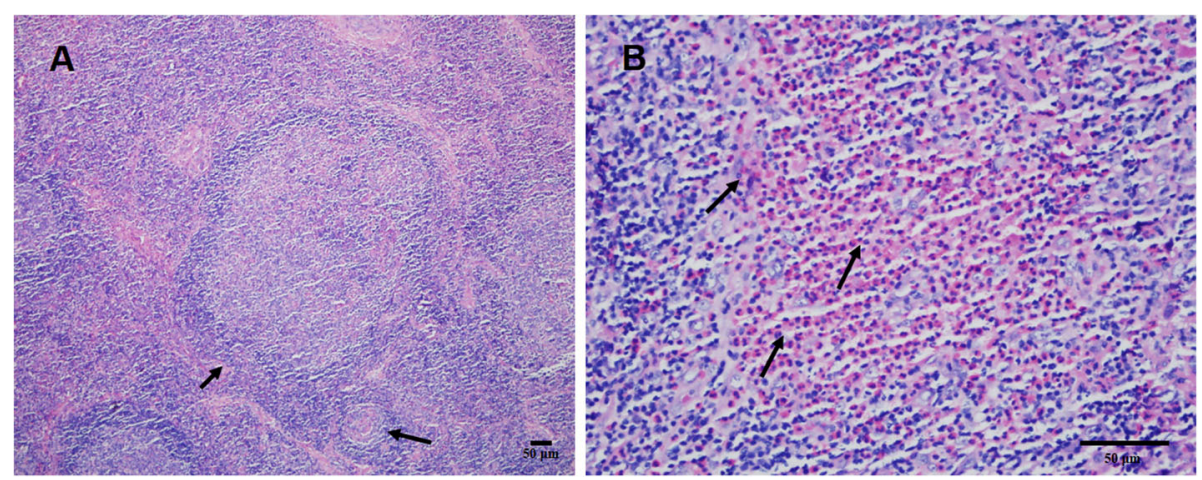

Fig. 1 Histological examination of a lymph node biopsy. a. The micrograph shows reactive follicles and vascular proliferation (arrow; H\&E staining $\times 100$ ); $\mathbf{b}$. Image showing eosinophil in filtration and the formation of an eosinophilic microabscess (arrow; H\&E staining $\times 400$ ) 


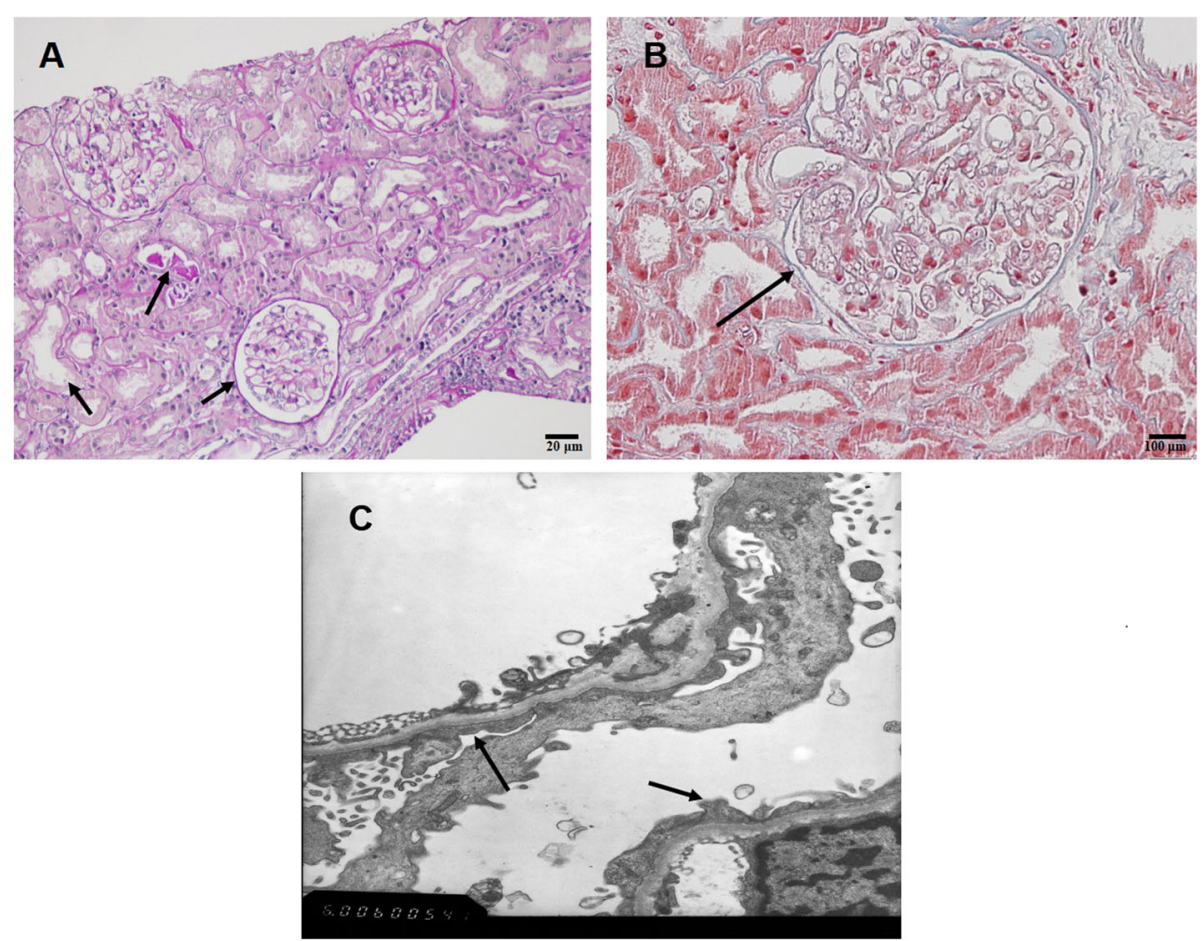

Fig. 2 Histological examination of a renal biopsy. a. Light microscopy image showing the basically normal of the glomerulus with a flattened renal tubular epithelium, a slightly dilated lumen, and the presence of a few protein cysts in the dilated tubules (arrow; H\&E staining $\times 200$ ). $\mathbf{b}$. Image of a minor glomerular lesion(arrow; H\&E staining $\times 400$ ). C. electron microscopy image showing mild hyperplasia of the mesangial cells and stromal cells and the extensive fusing of podocyte processes of the epithelial cells (arrow)

and significantly increased urine output compared with pre-treatment values. However, the patient's proteinuria increased to7.02 g/day.

The patient withdrew from hemodialysis and continued taking $40 \mathrm{mg} /$ day prednisolone after discharge, but returned to our hospital after 6 weeks. At that time, urinalysis revealed $1+$ proteinuria. The serum albumin concentration was $37.5 \mathrm{~g} / \mathrm{L}$, the serum creatinine concentration was $69.4 \mu \mathrm{mol} / \mathrm{L}$, the BUN concentration was $12.55 \mathrm{mmol} / \mathrm{L}$, and the eGFR was $97.8 \mathrm{~mL} / \mathrm{min} / \mathrm{m}^{2}$. The changes in the patient's laboratory indexes are shown in Fig. 3.

\section{Literature review}

Several databases, including PubMed, EMBASE, MEDLINE (Ovid), the Chinese National Knowledge

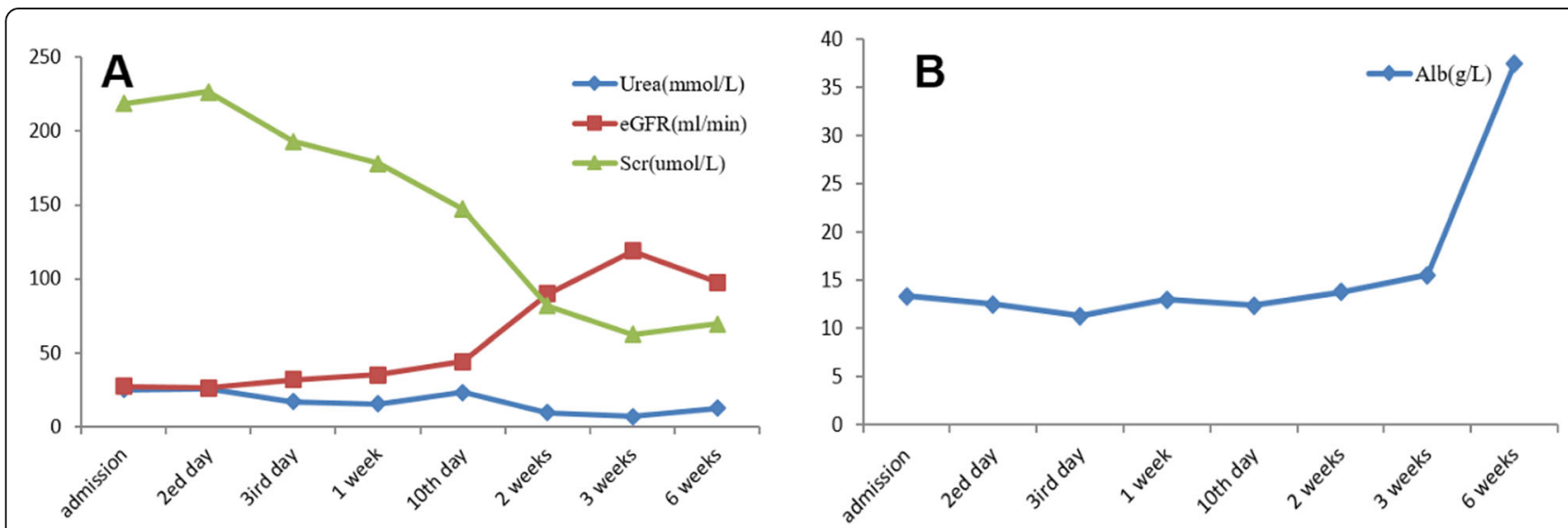

Fig. 3 Serial biochemical changes observed in the patient. a. The change in renal function. After 6 weeks of treatment, the urea nitrogen concentration decreased to $12.55 \mathrm{mmol} / \mathrm{L}$, the serum creatinine concentration decreased to $69.4 \mu \mathrm{mol} / \mathrm{L}$ and the eGFR increased to $97.8 \mathrm{~mL} / \mathrm{min}$. $\mathbf{b}$. The change in serum albumin concentrations. The serum albumin concentration increased to $37.5 \mathrm{~g} / \mathrm{L}$ after 6 weeks of treatment 
Infrastructure (CNKI), the VIP Database for Chinese Technical Periodicals (VIP), and WanFang Data, were systematically searched from the date of database inception until Nov 01, 2017 to collect published international and domestic studies with the term "Kimura's disease" and "Nephrotic syndrome". The selection criteria were as follows: 1 ). studies including patients who were diagnosed with $\mathrm{KD}$ by lymph node or mass biopsy; 2). studies in which renal involvement was noted in all patients, and renal biopsy was used to define the pathology. The exclusion criteria were as follows: 1). studies which the patients were diagnosed with Kimura's disease but with no renal involvement; 2). the data provided by the articles could not be accessed, or the full text could not be transformed. 3). the articles were reviews or abstracts. Ultimately, 18 studies $[5,7$, 9-24] were included in the analysis. 8 studies [5, 7, 911, 13, 22, 24] were published in English, and the others were published in Chinese. 26 patients were involved in this review. 20 patients were from China, 2 were from India, and one each was from Japan, Turkey, Vietnam, and Egypt (Table 1).

Of the 26 patients included in the review, two were female and were from China and India, respectively, and the remaining patients were male. Thus, the male-to-female ratio was 12:1. Most of the patients

Table 1 Clinical features, pathology of the kidney and lymph nodes and treatments administered of 26 patients with KD-associated nephrotic syndrome

\begin{tabular}{|c|c|c|c|c|c|c|c|c|c|c|c|}
\hline $\begin{array}{l}\text { Reported } \\
\text { by }\end{array}$ & Case & Country & Gender & Age & $\begin{array}{l}\text { Urine } \\
\text { protein } \\
(\mathrm{g} / 24 \mathrm{~h})\end{array}$ & $\begin{array}{l}\text { Serum } \\
\text { albumin } \\
(\mathrm{g} / \mathrm{L})\end{array}$ & $\begin{array}{l}\text { Serum creatinine } \\
\text { (umol/L) }\end{array}$ & $\begin{array}{l}\text { Serum } \\
\operatorname{lgE} \\
(\mathrm{IU} / \mathrm{ml})\end{array}$ & $\begin{array}{l}\text { Eosinophils } \\
(\%)\end{array}$ & Renal biopsy & Treatment \\
\hline X W Xiao & 1 & China & Male & 23 & 12.77 & 34.6 & 88 & 582 & 0.44 & Mesangial proliferation & Steroid+TW \\
\hline X F Zhang & 2 & China & Male & 46 & 6 & 26.3 & 62.9 & 43.4 & 0.15 & Minimal change disease & Steroid \\
\hline P C Li & 3 & China & Male & 49 & 10.07 & 15.7 & 75 & & 0.27 & Mesangial proliferation & Steroid \\
\hline H Sun & 4 & China & Male & 40 & 8.34 & 30.8 & 480 & & 0.15 & Acute tubular necrosis & Steroid \\
\hline Y W Zhang & 5 & China & Male & 23 & 6.05 & 23 & & 2500 & & IgA nephropathy & Steroid+CTX \\
\hline L L Shao & 6 & China & Male & 42 & 0.27 & & 131 & 1316 & 0.354 & IgA nephropathy & MMF \\
\hline$J$ L Meng & 7 & China & Male & 43 & 6 & 15.5 & 115 & & 0.574 & $\begin{array}{l}\text { Membranous } \\
\text { nephropathy }\end{array}$ & Steroid \\
\hline \multirow[t]{2}{*}{ R Duan } & 8 & China & Male & 19 & & 39.9 & 944 & 3000 & 0.154 & FSGS & Steroid \\
\hline & 9 & China & Femal & 35 & 0.84 & 31.2 & & 500 & 0.015 & Mesangial proliferation & Steroid \\
\hline \multirow[t]{8}{*}{ C B Liu } & 10 & China & Male & 19 & 3.65 & & 97.1 & 272 & 0.32 & $\begin{array}{l}\text { Membranous } \\
\text { nephropathy }\end{array}$ & Steroid \\
\hline & 11 & China & Male & 21 & 5.32 & & 185 & 397 & 0.17 & IgA nephropathy & Steroid+TW \\
\hline & 12 & China & Male & 36 & 14.1 & & 123.76 & 620 & 0.1 & $\begin{array}{l}\text { Membranous } \\
\text { nephropathy }\end{array}$ & Steroid+CTX \\
\hline & 13 & China & Male & 25 & 12.8 & & 88.4 & 989 & 0.44 & Mesangial proliferation & Steroid+TW \\
\hline & 14 & China & Male & 14 & 8.65 & & 53.04 & 172 & 0.056 & Mesangial proliferation & Steroid+LEF \\
\hline & 15 & China & Male & 44 & 7.28 & & 44.2 & 107 & 0.168 & Mesangial proliferation & Steroid+LEF \\
\hline & 16 & China & Male & 53 & 6.99 & & 176.8 & 160 & 0.122 & Mesangial proliferation & Steroid $+C T X$ \\
\hline & 17 & China & Male & 48 & 5.27 & & 79.56 & 1378 & 0.26 & $\begin{array}{l}\text { Membranous } \\
\text { nephropathy }\end{array}$ & Steroid \\
\hline Y G Sha & 18 & China & Male & 5 & 3.5 & 20.6 & 30 & 2000 & 0.21 & Mesangial proliferation & Steroid \\
\hline Koich & 19 & Japan & Male & 9 & 11.1 & 12 & 238 & 4981 & 0.48 & Minimal change disease & Steroid \\
\hline Fatih & 20 & Turkey & Male & 21 & 17.3 & 10 & 256 & 1987 & 0.21 & FSGS & Steroid+CsA \\
\hline Deepak & 21 & Vietnam & Male & 14 & 4 & 21 & 123 & & 0.11 & Mesangial proliferation & Steroid \\
\hline Chan & 22 & China & Male & 25 & 19.7 & 18 & 85 & 1918 & & Mesangial proliferation & Steroid \\
\hline S L Zhu & 23 & China & Male & 23 & 9.3 & 16 & & 1510 & 0.485 & FSGS & Steroid \\
\hline Mohamed & 24 & Egypt & Male & 50 & 8.9 & 9 & 212 & & 0.2 & $\begin{array}{l}\text { Membranous } \\
\text { nephropathy }\end{array}$ & $\begin{array}{l}\text { Steroid } \\
+\mathrm{MMF}\end{array}$ \\
\hline K Sud & 25 & India & Femal & 24 & 4.1 & 15 & 160 & & & Minimal change disease & Steroid \\
\hline Surendra & 26 & India & Male & 18 & 8.6 & 21 & 62 & & 0.03 & Mesangial proliferation & Steroid \\
\hline
\end{tabular}


presented with cervical lymphadenopathy or subcutaneous masses in the head or neck region. The mean age of these patients was $31.1 \pm 14.2$ years, the daily protein excretion level was $8.04 \pm 4.62 \mathrm{~g} / 24 \mathrm{~h}$, the serum albumin concentration was $21.2 \pm 8.57 \mathrm{~g} / \mathrm{L}$, the serum creatinine concentration was $170 \pm 190 \mu \mathrm{mol} / \mathrm{L}$, the blood eosinophil count was $23.7 \pm 15.4 \%$, and the IgE titer was $1285 \pm 1223 \mathrm{IU} / \mathrm{mL}$.

Renal biopsy was performed in all patients. Most of the patients presented with mesangial proliferative glomerulonephritis (13 patients). Other patients presented with membranous nephropathy (4 patients), minimal change disease (3 patients), focal segmental glomerulosclerosis (3 patients), IgA nephropathy (2 patients) and acute tubular injury (1 patient).

The majority of patients were treated with corticosteroids alone, while a small number of patients received corticosteroids combined with immunosuppressive agents, such as Tripterygium wilfordii, cyclophosphamide and leflunomide. With the exception of 2 patients who progressed to ESRD (end stage renal disease) and received hemodialysis, all other patients achieved remission with respect to their proteinuria. Simultaneously, the neck lymph nodes or masses became smaller. However, 5 patients experienced a proteinuria relapse during follow-up, including 4 patients with mesangial proliferative glomerulonephritis and one patient with membranous nephropathy.

\section{Discussion and conclusion}

KD presents as a benign subcutaneous mass, and males are affected by KD more often than females. However, $\mathrm{KD}$ combined with kidney involvement is not rare. According to previous reports in the literature, kidney involvement often presents after the skin changes have been present for a few months. Regarding the patients who have kidney involvement associated with KD, 12$16 \%$ have proteinuria, and $59-78 \%$ have nephrotic syndrome $[6,25,26]$. The renal disease affecting the patients in our report was nephrotic syndrome.

Wang et al.[27]analyzed the clinical presentations of 20 patients with KD-associated nephrotic syndrome in China and found that men were predominantly affected by the disease, as the male: female ratio in their study was 19:1. The average proteinuria level in these patients was $8.67 \pm 4.73 \mathrm{~g} /$ day. Renal biopsy was performed in 13 patients and showed that various forms of renal pathology were present. 9 patients had mesangial proliferative glomerulonephritis, 2 had MCD, and 2 had membranous nephropathy. Although mesangial proliferative glomerulonephritis was the most common disease demonstrated by renal biopsy in the review, MCD combined with acute renal tubular injury was demonstrated by renal biopsy in this report.
Although some patients with KD suffer from kidney disease, the pathogenesis of $\mathrm{KD}$ and its associated renal involvement is not very clear. Several studies of the immunopathogenic features of the disease found that the pathogenesis of $\mathrm{KD}$ with renal involvement may be related to high serum IgE levels and eosinophilia [9]. In addition, some authors have speculated that viral infections or toxins alter $\mathrm{T}$ cell immunoregulatory functions or induce IgE-mediated type I hypersensitivity, resulting in the release of lymphokines [11, 27]. As shown in the study by Liu $C$ et al. [26], peripheral blood CD4+ and CD8+ T cell counts were significantly increased in patients with KD presenting with renal involvement, a finding that have may indicate $\mathrm{Th}$ cell immunoactivity. Th cells secrete cytokines to chemoattract B cells, mast cells and eosinophils and to promote the growth and differentiation of the cells at the site of an immune response.IL-4, which is expressed by T-helper 2 (Th2) cells and is not only an inducer of Th2 differentiation but also an eosinophil attractor, promotes B-cell class switching to IgE, resulting in high serum IgE levels. In addition, Katagiri et al. [28] found that TNF- $\alpha$, IL-4, IL-5 and IL-13 mRNA levels in patients with KD were elevated before treatment but decreased markedly after surgery and radiation therapy. This observation supports the idea that Th2 cytokines play a part in KD development. According to Kimura et al. [29], T cells and mast cells play important roles in the pathogenesis of $K D$, a finding based on the observation that Th2-type cytokine and chemokine levels were increased in patients with the disease. These immunological triggers may result in the lymph node alterations characteristic of and the renal lesions associated with the disease.

Corticosteroids are particularly applicable for the treatment of KD with renal involvement [30], as they can improve proteinuria in patients with nephrotic syndrome by suppressing the transcription of inflammatory mediator genes [31]. However, termination of or reduction in steroid therapy often results in the recurrence of masses and proteinuria. Therefore, some patients require corticosteroids combined with immunosuppressive agents, such as cyclophosphamide and cyclosporine (CsA) [3234]. Katagiri et al. [28] reported that CsA suppresses the activity of Th2 cytokines, which play an important role in KD development. Other therapies include irradiation and surgical removal. However, mass re-growth is common after surgical resection [35].

This report is about a singular manifestation of KD. Our patient, a middle-aged male, presented with atypical KD with renal involvement that responded well to steroids. The patient did not experience recurrence of either his skin lesions or his nephrotic syndrome during the follow-up period. We used corticosteroids alone, 
which successfully restored the patient's renal function to normal. However, our follow-up time was short, and the long-term efficacy of the above treatment needs confirmation. In summary, steroids are still the first-choice treatment for $\mathrm{KD}$ with renal involvement but can be combined with immunosuppressive drugs if proteinuria persists.

MCD combined with acute renal tubular injury is rare in patients with $\mathrm{KD}$ presenting with renal involvement. Corticosteroids may be a beneficial treatment for renal injury in patients with $\mathrm{KD}$.

\section{Abbreviations}

ADA: Adenosine deaminase; CSA: Cyclosporine; ESRD: End-stage renal disease; KD: Kimura's disease; MCD: Minimal change disease

\section{Acknowledgements}

The authors thank the patient and his family for their support. The authors also thank Dr. Fanghua Li from the Department of Pathology, Sichuan Provincial People's Hospital for his generous technical support.

\section{Funding}

This work was supported by grants from the National Natural Science Foundation of China (Grant No. 81300618 to Xiang Zhong), the Sichuan Provincial Planning Commission Fund (Grant No. 17PJ058 to Xiang Zhong), the Sichuan Provincial People's Hospital Research Foundation (Grant No. 2016 L707 to Xiang Zhong), and the Youth Science and Technology Creative Research Groups of Sichuan Province (Grant No. $2015 T D 0013$ to Gui Sen Li).

\section{Availability of data and materials}

All data collected from this patient were obtained from the Sichuan Provincial People's Hospital and are available in this paper.

\section{Authors' contributions}

Research concept: SR and $X Z$; search and systematic review: $S R, X L$ and $X Z$; data extraction and literature review: SR, XL, FW, PZ, YZ and XZ; statistical analysis: $S R, X L, F W, P Z, Y Z$ and $X Z$. This work was supervised by $G L$ and $L W$, the manuscript was drafted by $S R, X L$ and $X Z$, and $G L$ and $L W$ were responsible for revising the manuscript. All authors have read and approved the manuscript.

\section{Ethics approval and consent to participate}

The case report was approved by the Medical Ethics Committee of the Sichuan Academy of Medical Sciences \& Sichuan Provincial People's Hospital. The patient provided written informed consent for participation in the study at Sichuan Provincial People's Hospital.

\section{Consent for publication}

The patient received all information regarding this case report. Written informed consent for publication in BMC Nephrology was obtained from the patient.

\section{Competing interests}

The authors have no competing interests to declare.

\section{Publisher's Note}

Springer Nature remains neutral with regard to jurisdictional claims in published maps and institutional affiliations.

Received: 8 December 2017 Accepted: 26 October 2018

Published online: 08 November 2018

\section{References}

1. Kim HSC. Eosinophilic hyperplastic lymphogranuloma, comparison with Mikulicz's disease. Chin Med J. 1937;23:699-700.

2. Romao JE, Saldanha LB, lanez LE, Sabbaga E. Recurrence of focal segmental glomerulosclerosis associated with Kimura's disease after kidney transplantation. Am J Kidney Dis. 1998;31(3):E3.
3. Abuel-Haija M, Hurford MT. Kimura disease. Archives of pathology \& laboratory medicine. 2007;131(4):650-1.

4. Armstrong WB, Allison G, Pena F, Kim JK. Kimura's disease: two case reports and a literature review. Ann Otol Rhinol Laryngol. 1998;107(12):1066-71.

5. Matsumoto K, Katayama H, Hatano M. Minimal-change nephrotic syndrome associated with subcutaneous eosinophilic lymphoid granuloma (Kimura's disease). Nephron. 1988;49(3):251-4

6. Yamada A, Mitsuhashi K, Miyakawa Y, Kosaka K, Takehara K, lijima M, Tanaka K, Shibata S. Membranous glomerulonephritis associated with eosinophilic lymphfolliculosis of the skin (Kimura's disease): report of a case and review of the literature. Clin Nephrol. 1982;18(4):211-5.

7. Dede F, Ayli D, Atilgan KG, Yuksel C, Duranay M, Sener D, Turker F. Focal segmental glomerulosclerosis associating Kimura disease. Ren Fail. 2005;27(3):353-5.

8. Natov SN, Strom JA, Ucci A. Relapsing nephrotic syndrome in a patient with Kimura's disease and IgA glomerulonephritis. Nephrol Dial Transplant. 1998; 13(9):2358-63.

9. Chan TM, Chan PC, Chan KW, Cheng IK. IgM nephropathy in a patient with Kimura's disease. Nephron. 1991;58(4):489-90.

10. Sud K, Saha T, Das A, Kakkar N, Jha V, Kohli HS, Sakhuja V. Kimura's disease and minimal-change nephrotic syndrome. Nephrol Dial Transplant. 1996; 11(7):1349-51.

11. Rajpoot DK, Pahl M, Clark J. Nephrotic syndrome associated with Kimura disease. Pediatr Nephrol. 2000;14(6):486-8.

12. Xiao $X$, Shi $Y$, Song $Y$. Kimura's disease associated with nephrotic syndrome: a case report. Chin J Intern Med [Transl]. 2004;43(02):69-70.

13. Liu C, Hu W, Chen H, Tang Z, Zeng C, Liu Z, Li L. Clinical and pathological study of Kimura's disease with renal involvement; 2008.

14. Zhang X, Sun Z, Wang L, Qi Z. A case of kimura disease of papillary gland with nephrotic syndrome. Chin J Clin Oncol [Transl]. 2009;36(19):1085.

15. Fouda MA, Gheith $\mathrm{O}$, Refaie A, El-Saeed M, Bakr A, Wafa E, Abdelraheem M, Sobh M. Kimura disease: a case report and review of the literature with a new management protocol. International journal of nephrology. 2011;2010:673908.

16. Li C, Chen H, Yang Z, Wang J, Gan M, Xu G. Renal involvement in Kimura's disease: a case report. New Med [Transl]. 2012;43(10):752-3.

17. Sun H, Fan R, Gong D. Nursing care of one patient with Kimura disease complicated with acute renal tubular necrosis. Chin J Misdiagnostics Transl]. 2012;12(06):1509.

18. Zhang $Y$, Wang $Y$, Zhang A. A cases of Kimura disease with renal damage and review of the literature. In study class in Sandong Province ninth rheumatology conference and rheumatic disease biological treatment [Translation]. 2012.

19. Shao L, He Q, Wang H, Chen J. Kimura's disease complicated with IgA nephropathy: a case report. Zhejiang Med [Translation]. 2013;35(21):1947+1949.

20. Meng J, Wu J, Liu S, Xie Y, Cai G, Chen X. Kimura's disease complicated with nephrotic syndrome: a case report. Chin J Kidney Dis Investig [Transl]. 2014; 3(01):45-47.

21. Duan R, He Z, Hu Z. two cases of Kimura's disease complicated with kidney injury. W China Med J [Transl]. 2015;30(06):1192-4.

22. Rathore SS, Arora P, Usha, Prakash J. Mesangioproliferative glomerulonephritis in a patient with Kimura's disease presenting as nephrotic syndrome. Saudi J Kidney Dis Transpl. 2015;26(1):115-8.

23. Sha Y, Zhao F, Zhu C, Ding G. Mesangial proliferative glomerulonephritis in children with Kimura disease : a cases report. J Nanjing Med Univ [Transl]. 2015;35(06):895-8.

24. Zhu SL, Wei PF, Chen JH, Zhao ZF, Xu QN, Ye L. Diagnosis and treatment of a patient with Kimura's disease associated with nephrotic syndrome and lymphadenopathy of the epitrochlear nodes. BMC Nephrol. 2015;16:10.

25. Matsuda O, Makiguchi K, Ishibashi K, Chida Y, Ida T, Matsuda K, Tomita K, Marumo F, Hiruma M. Long-term effects of steroid treatment on nephrotic syndrome associated with Kimura's disease and a review of the literature. Clin Nephrol. 1992:37(3):119-23.

26. Liu C, Hu W, Chen H, Tang Z, Zeng C, Liu Z, Li L. Clinical and pathological study of Kimura's disease with renal involvement. J nephrology. 2008;21(4):517-25.

27. Wang DY, Mao JH, Zhang Y, Gu WZ, Zhao SA, Chen YF, Liu AM: Kimura disease: a case report and review of the Chinese literature. Nephron Clinical practice 2009, 111(1):c55-c61.

28. Katagiri K, Itami S, Hatano Y, Yamaguchi T, Takayasu S. In vivo expression of IL-4, IL-5, IL-13 and IFN-gamma mRNAs in peripheral blood mononuclear cells and effect of cyclosporin a in a patient with Kimura's disease. $\mathrm{Br} J$ Dermatol. 1997;137(6):972-7. 
29. Kimura Y, Pawankar R, Aoki M, Niimi Y, Kawana S. Mast cells and T cells in Kimura's disease express increased levels of interleukin-4, interleukin-5, eotaxin and RANTES. Clin Exp Allergy. 2002;32(12):1787-93.

30. Senel MF, Van Buren CT, Etheridge WB, Barcenas C, Jammal C, Kahan BD. Effects of cyclosporine, azathioprine and prednisone on Kimura's disease and focal segmental glomerulosclerosis in renal transplant patients. Clin Nephrol. 1996;45(1):18-21.

31. Nakahara C, Wada T, Kusakari J, Kanemoto K, Kinugasa H, Sibasaki M, Nagata M, Matsui A. Steroid-sensitive nephrotic syndrome associated with Kimura disease. Pediatr Nephrol. 2000;14(6):482-5.

32. Sato S, Kawashima H, Kuboshima S, Watanabe K, Kashiwagi Y, Takekuma K, Hoshika A. Combined treatment of steroids and cyclosporine in Kimura disease. Pediatrics. 2006;118(3):e921-3.

33. YS W, YK T, E T, WT P. Treatment of Kimura's disease with cyclosporine. J Dermatolog Treat. 2005;16:242-4.

34. Soeria-Atmadja S, Oskarsson T, Celci G, Sander B, Berg U, Gustafsson B. Maintenance of remission with cyclosporine in paediatric patients with Kimura's disease - two case reports. Acta Paediatr. 2011;100(10):e186-9.

35. TA D, F A, DK H, RF A. treatment of Kimura's disease: a therapeutic enigma. Otololaryngol Head Neck Surg. 1995;112:333-7.

Ready to submit your research? Choose BMC and benefit from:

- fast, convenient online submission

- thorough peer review by experienced researchers in your field

- rapid publication on acceptance

- support for research data, including large and complex data types

- gold Open Access which fosters wider collaboration and increased citations

- maximum visibility for your research: over $100 \mathrm{M}$ website views per year

At $\mathrm{BMC}$, research is always in progress.

Learn more biomedcentral.com/submissions 